\title{
A Point Mutation at the C-Terminal Half of the Repressor of Temperate Mycobacteriophage L1 Affects Its Binding to the Operator DNA
}

\author{
Tridib Ganguly, Partho Chattoraj, Malabika Das, Palas K. Chanda, \\ Nitai. C. Mandal, Chia Y. Lee ${ }^{\dagger}$ and Subrata Sau* \\ Department of Biochemistry, Bose Institute, P1/12-CIT Scheme VII M, Calcutta 700 054, India \\ 'Department of Microbiology, Molecular Genetics and Immunology, University of Kansas Medical Center, \\ 3901 Rainbow Blvd., Kansas City, Kansas 66160, USA
}

Received 31 March 2004, Accepted 6 July 2004

\begin{abstract}
The wild-type repressor CI of temperate mycobacteriophage $\mathrm{L1}$ and the temperature-sensitive (ts) repressor CIts391 of a mutant L1 phage, L1cIts391, have been separately overexpressed in $E$. coli. Both these repressors were observed to specifically bind with the same cognate operator DNA. The operator-binding activity of CIts391 was shown to differ significantly than that of the $\mathrm{CI}$ at 32 to $42^{\circ} \mathrm{C}$. While 40-95\% operator-binding activity was shown to be retained at 35 to $42^{\circ} \mathrm{C}$ in $\mathrm{CI}$, more than $75 \%$ operator-binding activity was lost in CIts391 at 35 to $38^{\circ} \mathrm{C}$, although the latter showed only $10 \%$ less binding compared to that of the former at $32^{\circ} \mathrm{C}$. The CIts391 showed almost no binding at $4^{\circ} \mathrm{C}$. An in vivo study showed that the CI repressor inhibited the growth of a clear plaque former mutant of the L1 phage more strongly than that of the CIts391 repressor at both 32 and $42^{\circ} \mathrm{C}$. The half-life of the CIts391-operator complex was found to be about 8 times less than that of the CI-operator complex at $32^{\circ} \mathrm{C}$. Interestingly, the repressoroperator complexes preformed at $0^{\circ} \mathrm{C}$ have shown varying degrees of resistance to dissociation at the temperatures which inhibit the formation of these complexes are inhibited. The CI repressor, but not that of CIts391, regains most of the DNA-binding activity on cooling to $32^{\circ} \mathrm{C}$ after preincubation at 42 to $52^{\circ} \mathrm{C}$. All these data suggest that the $131^{\text {st }}$ proline residue at the $\mathrm{C}$-terminal half of $\mathrm{CI}$, which changed to leucine in the CIts391, plays a crucial role in binding the $\mathrm{L} 1$ repressor to the cognate operator DNA, although the helix-turn-helix DNA-binding motif of the L1 repressor is located at its $\mathrm{N}$-terminal end.
\end{abstract}

Keywords: Gel shift assay, Mycobacteriophage L1, Temperaturesensitive mutant CIts391 repressor, Wild-type CI repressor

*To whom correspondence should be addressed.

Tel: 91-33-2337-9416; Fax: 91-33-2334-3886

E-mail: sau@bic.boseinst.ernet.in

\section{Introduction}

Mycobacteriophage L1 is a temperate phage, whose natural host is an unspeciated Mycobacterium ATCC27199 (Doke, 1960). It has a $50 \mathrm{~kb}$ double-stranded DNA genome, which remains integrated at a specific site in the chromosome of $M$. smegmatis (Snapper et al., 1988). Genetic studies have shown that the $c$ I gene of L1 is essential for both the establishment and maintenance of lysogeny, and the lysogen of L1 carrying a temperature-sensitive mutation in its $c \mathrm{I}$ gene is induced at non-permissive temperatures (Chaudhuri et al., 1993). This suggests that the $c \mathrm{I}$ gene of $\mathrm{L} 1$ codes for its repressor. The $c \mathrm{I}$ gene is located at the left-hand side in around $15 \%$ of the coordinates of its genome (Chaudhuri et al., 1993). The wildtype $c \mathrm{I}$ and mutant $c \mathrm{Its} 391$ genes of L1 were cloned and sequenced (Sau et al., 2004). Sequence analysis showed that the $c$ I gene encodes a 183 amino acid residue protein, and in the CIts391 repressor, the proline residue at the $131^{\text {st }}$ position is replaced by leucine. Incidentally, the amino acid sequence of the CI repressor of L1 (Sau et al., 2004) was found to be $100 \%$ identical to that of the repressor gp71 of the homoimmune phage L5 (Hatfull, 2000). L5 gp71 negatively regulates the transcription from the early promoter, $P_{\text {left }}$ and was shown to bind at a specific operator region encompassing the-35 element of the promoter, $P_{\text {left }}$ (Hatfull, 2000). The promoter, having $100 \%$ sequence similarity with the $P_{\text {left }}$ of L5, was also recently cloned from phage L1 (Chattopadhyay et al., 2003). Interestingly, the operator present in $P_{\text {left }}$ was also present in 29 other locations within the L5 genome (Hatfull, 2000).

The temperature-sensitive repressors of lambda (Mandal and Leib, 1976; Jana et al., 1999), P1 (Heinrich et al., 1989) and $\mathrm{Mu}$ (Vogel et al., 1991) have been used as model systems to study the structure-function relationship of these negative regulatory proteins and to construct several genetic tools (Sambrook et al., 1989). Several mutants carrying the 
temperature-sensitive mutations in the repressor gene were also isolated from both mycobacteriophages L1 (Chaudhuri et al., 1993) and L5 (Donnelly-wu et al., 1993), and the mutations mapped (Donnelly-wu et al., 1993; Sau et al., 2004). However, such mutant repressors remain to be exploited at length in the elucidation of the structure-function relationship of any mycobacteriophage-specific repressor. In the present communication, in order to decipher the role of the $131^{\text {st }}$ proline residue on the structure and function of the L1 repressor, both the wild-type and the CIts391 repressors were overexpressed and their operator DNA-binding activities compared at different temperatures. Our data suggests that the point mutation resulting in the P131L change in the CIts391 repressor significantly affects its binding to the operator at $32^{\circ} \mathrm{C}$ and above.

\section{Materials and Methods}

Bacterial and phage strains, plasmids and growth conditions M. smegmatis $\mathrm{mc}^{2} 155$ and LR222, were obtained from Dr. Anil Tyagi (University of Delhi, South Campus, New Delhi, India), and routinely grown in Middlebrook 7H9 medium (Chaudhuri et al., 1993). The wild-type mycobacteriophage L1, its mutants $\mathrm{L}_{1} \mathrm{I}^{-}$and L1cIts391, and their assay procedures have been described previously (Chaudhuri et al., 1993). The E. coli-M. smegmatis shuttle vector pSD5S30, containing a mycobacteria-specific promoter S30, was obtained from Dr. Anil Tyagi (University of Delhi, South Campus, India). The vector pMPMK4 (Mayer, 1995) was a generous gift from Dr. S. Yasuda (Japan).

DNA isolations and manipulations Genomic DNAs were isolated from both the wild-type L1 and mutant L1cIts391 phages, according to the standard procedure (Sau et al., 2004). The $c \mathrm{I}$ and cIts391 genes were amplified by Taq polymerase using the above genomic DNAs as templates and the same pair of primers; LCP2 (5'-AAGCTTCCTTTCGTTGCGCGGC) and LCP3 (5'-GAATTC ATGAGCGGCAAAATC). The resulting fragments were cloned separately into a TA cloning vector, according to the manufacturer's protocol (Invitrogen Inc., Carlsbad, USA). The recombinant TA vectors carrying the $c \mathrm{I}$ and $c \mathrm{I} t s 391$ genes were designated pSAU1047 and pSAU1076, respectively. Sequences of the repressor genes were confirmed by the sequencing of the inserts of both pSAU1047 and pSAU1076 using an ABI automated sequencer, according to the manufacturer's protocol. All other molecular biological techniques, including plasmid DNA isolation, digestion of DNA by restriction enzymes, ligation by T4 DNA ligase, transformation, etc. were carried out according to the standard procedures (Sambrook and Russell, 2001). All the restriction \& modifying enzymes, PCR kits and oligonucleotides were purchased from Bangalore Genei (India).

Overexpression of the wild-type CI and CIts391 repressors To overexpress the wild-type CI and CIts391 repressors, the $c \mathrm{I}$ and cIts391 genes, generated from pSAU1047 and pSAU1076, respectively, were separately subcloned downstream of the Larabinose inducible promoter, $p B A D$, in an $E$. coli-specific expression vector, pMPMK4 (Mayer, 1995). The resulting pMPMK4 derivatives carrying the $c \mathrm{I}$ and $c \mathrm{I} t s 391$ genes were named pSAU1049 and pSAU1085, respectively.

E. coli $\mathrm{DH} 5 \alpha$ cells carrying pSAU1049 were grown for $16 \mathrm{~h}$ at $32^{\circ} \mathrm{C}$ in the presence of $0.1(\mathrm{w} / \mathrm{v}) \mathrm{L}$-arabinose and then harvested by centrifugation. The cell pellet was resuspended in 1/10 volume of TEN buffer (10 mM Tris-Cl, pH 7.9, $1 \mathrm{mM}$ EDTA and $50 \mathrm{mM}$ $\mathrm{NaCl}$ ) and sonicated with $5-30 \mathrm{sec}$ pulses at $100 \mathrm{~W}$ using a sonicator (Microsonics XL2000). The extract was centrifuged at $37,000 \mathrm{rpm}$ at $4^{\circ} \mathrm{C}$, and both the supernatant and pellet fractions were stored on ice till used. The proteins in these cell extracts were estimated by a standard procedure (Bradford, 1976) and those in the different fractions analyzed by SDS-PAGE (Ausubel et al., 1998). A protein band having a size $(\sim 21 \mathrm{kDa})$ similar to that of the L1 repressor was found in the extracts made from the induced $E$. coli cells carrying pSAU1049 only (data not shown).

The cell extracts were prepared from E. coli $\mathrm{DH} 5 \alpha$ (pSAU1085) cells by the same procedure described above. As shown in the case of the wild-type $\mathrm{L} 1$ repressor above, a $21 \mathrm{kDa}$ protein was also detected in the extracts prepared from the induced E. coli cells carrying pSAU1085 only (data not shown).

Gel shift assay For the gel shift assay, a $97 \mathrm{bp}$ Pst $\mathrm{I}-$ BamHI fragment of L1 DNA, equivalent to 51740-51644 bp co-ordinate of L5 genome carrying one repressor binding site at the immediate upstream of the promoter, $P_{l e f \text {, }}$ (Brown et al., 1997) was cloned in a separate study and used here as an operator DNA in the gel shift assay. It was end-labeled with $\left[{ }^{32} \mathrm{P}-\gamma\right]$ ATP, according to the standard procedure (Sambrook and Russell, 2001). The gel shift assay was performed by a modification to the method of Brown et al., (1997). Briefly, an aliquot of the soluble extract, containing around $5 \mu \mathrm{g}$ protein, was mixed with $2 \eta \mathrm{g}$ of ${ }^{32} \mathrm{P}$ end- labeled operator DNA in a $20 \mu \mathrm{l}$ reaction mixture (containing $2 \mu \mathrm{g}$ of calf thymus DNA, 100 $\mu \mathrm{g} / \mathrm{ml}$ of BSA, $50 \mathrm{mM} \mathrm{NaCl}, 10 \mathrm{mM}$ Tris $\mathrm{pH} \mathrm{7.9,5 \%} \mathrm{glycerol} \mathrm{and}$ $1 \mathrm{mM}$ EDTA) and incubated on ice for $15 \mathrm{~min}$. The reaction was stopped by the addition of $3 \mu \mathrm{l}$ of loading dye (containing $5 \%$ glycerol and Bromophenol blue) and the samples loaded onto a prerun native polyacrylamide gel (6\% acrylamide, $1 \mathrm{X}$ TBE $\mathrm{pH} 8.3$ ) in $0.25 \mathrm{X}$ TBE buffer (Ouyang et al., 1999). After electrophoresis for $4 \mathrm{~h}$ at $50 \mathrm{~V}$, the gel was dried and autoradiographed. The autoradiographs were scanned either by a densitometer (Molecular Dynamics, USA) or by a Gel Doc 1000 system (BioRad, Hercules, USA). Each lane was scanned 3-5 times and the average value of each lane was used to determine the amount of both the bound (by L1 repressor) and free operator DNA that had been separated by the above gel electrophoresis. As demonstrated for many DNA-binding proteins before (Ausubel et al., 1998), the amount of operator DNA shifted (bound) by the L1 repressor was used as a direct measure of the operator DNA-binding activity of L1 repressor. For the incubation of the L1 repressor or L1 repressor-operator complexes at other temperatures, such as $32,35,38,42,45,48$ and $52^{\circ} \mathrm{C}$, different temperature-regulated water baths were used.

To see the effect of temperatures on the DNA binding activities of the L1 repressor, equal amounts $(5 \mu \mathrm{g})$ of E. coli cell extracts carrying either the wild-type or CIts391 repressors were incubated at $32,35,38$ and $42^{\circ} \mathrm{C}$ for $30 \mathrm{~min}$. Then, $2 \mu \mathrm{g}$ of ${ }^{32} \mathrm{P}$ end- labeled operator DNA was added to each extract and the incubation continued for another $20 \mathrm{~min}$. The rest of the steps of gel shift assay 
were the same as those described above.

To study the refolding of the L1 repressor, equal amounts $(5 \mu \mathrm{g})$ of $E$. coli cell extracts carrying either the wild-type or CIts391 repressors were incubated at $42,45,48$ and $52^{\circ} \mathrm{C}$ for $30 \mathrm{~min}$, and then cooled very slowly to $32^{\circ} \mathrm{C}$. An equal amount of ${ }^{32} \mathrm{P}$ endlabeled operator DNA was added to each extract and the reactions continued for $20 \mathrm{~min}$ at $32^{\circ} \mathrm{C}$. The rest of the steps of gel shift assay were performed according to the procedure described above.

To study the stability of the complexes formed between the wild type CI (or CIts391) and the operator at different temperatures, equal $(5 \mu \mathrm{g})$ amounts of $E$. coli extract were mixed with $2 \mu \mathrm{g}$ of ${ }^{32} \mathrm{P}$ end-labeled operator DNA at $0^{\circ} \mathrm{C}$ and incubated for about $1 \mathrm{~min}$. Then, the reaction mixtures were transferred to $32,42,45,48$ and $52^{\circ} \mathrm{C}$ incubators for $20 \mathrm{~min}$. Next, all the mixtures were resolved, autoradiographed and quantified by the procedures described above.

To study the rate of dissociation of the repressor-operator complexes at $32^{\circ} \mathrm{C}$, equal $(5 \mu \mathrm{g})$ amounts of $E$. coli cells extracts (carrying either the wild-type or L1CIts391 repressor) were mixed with $2 \eta \mathrm{g}$ of ${ }^{32} \mathrm{P}$ end-labeled operator DNA and incubated at $32^{\circ} \mathrm{C}$. After $20 \mathrm{~min}$, a 400 -fold excess of unlabeled operator DNA was added, and $25 \mu \mathrm{l}$ aliquots taken at $0,5,15,30,45,60$ and $90 \mathrm{~min}$. Each time the reaction was stopped by the addition of an equal volume of the sample loading buffer. These reaction mixtures were subjected to electrophoresis, autoradiographed and scanned by the procedures described above. The half-life of the repressor-operator complex was determined as the time point where $50 \%$ of the repressor-operator complex of the zero time point was present.

\section{Results and Discussion}

The wild-type CI and its mutant derivative, CIts391 bind to the same cognate operator specifically Ascertain that the $21 \mathrm{kDa}$ protein present in the extracts of the L-arabinose induced E. coli cells carrying pSAU1049 is indeed an L1specific repressor, a gel shift assay was performed using the ${ }^{32} \mathrm{P}$ end-labeled L1 operator DNA and different E. coli cell extracts. The results shown in Fig. 1 reveal that the operator DNA-binding activity (assayed at $0^{\circ} \mathrm{C}$ ) was present in the cell extract prepared from induced E. coli carrying pSAU1049 plasmid (lane 3) only, but in neither the same cells grown in the absence of the inducer (lane 2) nor the E. coli cells harboring no plasmid but grown in presence of L-arabinose (data not shown). The binding to the ${ }^{32} \mathrm{P}$-labeled operator DNA was competed with cold operator DNA (lane 4), but not with non-specific DNA (lane 5). It was concluded that this DNA-binding activity was specific for the operator DNA of L1. Identical DNA-binding results were also obtained with the extract prepared from the L-arabinose induced $E$. coli cells carrying pSAU1085 (data not shown). Therefore, the above 21 $\mathrm{kDa}$ protein was truly the $c \mathrm{I}$ gene-coded repressor of $\mathrm{L} 1$. The operator DNA-binding results also suggest that the L1 repressor expressed in the heterologous system of E. coli had attained biologically active conformation.

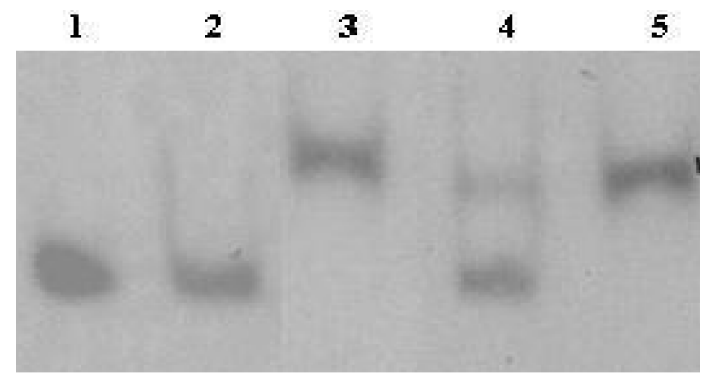

Fig. 1. Operator DNA-binding specificity of the L1 repressor. To determine the operator DNA-binding specificity of the L1 repressor, the gel shift assay was carried out according to the procedure described in Materials and Methods. Lanes: 1, endlabeled operator; 2, as of lane 1 plus uninduced $E$. coli (pSAU1049) cell extract; 3 , as of lane 1 plus induced $E$. coli (pSAU1049) extract; 4, as of lane 3 plus 100 fold excess of cold operator DNA; 5, as of lane 3 plus 100 fold excess of a DNA fragment carrying a truncated $E$. coli $\beta$-galactosidase gene. See text for details.

Comparison of the operator DNA binding activities between the wild-type $\mathrm{CI}$ and CIts391 repressors at different temperatures The temperate mycobacteriophage L1 forms turbid plaques on the lawn of M. smegmatis at both 32 and $42^{\circ} \mathrm{C}$, whereas, its mutant L1cIts391, forms turbid plaques at $32^{\circ} \mathrm{C}$, but clear plaques at $42^{\circ} \mathrm{C}$ (Chaudhuri et al., 1993). It was suggested that the point mutation present in CIts391 makes it more heat-labile compared to the wild-type repressor above $32^{\circ} \mathrm{C}$ (Sau et al., 2004). To determine whether the repressor CIts391 is really more thermosensitive than that of its wild-type counterpart, their operator DNA-binding activities were compared by gel shift assays at temperatures ranging from 32 to $42^{\circ} \mathrm{C}$. It was reasoned that a repressor, if sensitive to a particular temperature, would fail to bind its cognate operator DNA at that temperature, and as a result, the repressor-operator complex will not form. As shown in Fig. 2, the operator-binding activity of the wild-type repressor was affected nearly $5-10 \%$ at 35 to $38^{\circ} \mathrm{C}$ compared with that obtained at $32^{\circ} \mathrm{C}$ (lanes 2 versus $4 \& 6$ ). However, about $40 \%$ binding was found at $42^{\circ} \mathrm{C}$ (Fig. 2, lanes 2 versus 8). The binding activity of CI was dramatically reduced, to about $95-$ $98 \%$, at temperatures from 45 to $52^{\circ} \mathrm{C}$ (data not shown). On the contrary, the operator DNA-binding activity of the CIts391 repressor was estimated to be about $10 \%$ less than that of the wild-type $\mathrm{CI}$ at $32^{\circ} \mathrm{C}$ (Fig. 2, lanes 2 versus 3). Most notably, around $75 \%$ of the CIts391-specific activity was lost at 35 and $38^{\circ} \mathrm{C}$ (Fig. 2, lanes 3 versus $5 \& 7$ ), and at $42^{\circ} \mathrm{C}$ there was barely any CIts391 activity left (Fig. 2, lane 9). The data indeed indicates that the DNA-binding activity in the CIts391 repressor was more thermolabile than that in the wild-type repressor at $35^{\circ} \mathrm{C}$ and above. Such temperature-dependent behavior of CIts391 has not been previously reported for any other temperature-sensitive mycobacteriophage-specific repressor. 


$\begin{array}{llllllllll}1 & 2 & 3 & 4 & 5 & 6 & 7 & 8 & 9\end{array}$

Fig. 2. The effect of preincubation at different temperatures on the DNA-binding activities in L1 repressors. The gel shift assay picture showing the amount of complexes formed between the wild-type CI (or CIts391) repressor and operator DNA at different temperatures. See Materials and Methods for details. Lanes $2 \& 3,4 \& 5,6 \& 7$ and $8 \& 9$ contain reaction mixtures at $32,35,38$ and $42^{\circ} \mathrm{C}$, respectively. Lane 1 contains labeled operator only. The reaction mixtures containing the wild-type repressor were loaded into lanes 2, 4, 6 and 8, whereas, the mixtures carrying the CIts391 repressor were loaded into the remaining lanes.

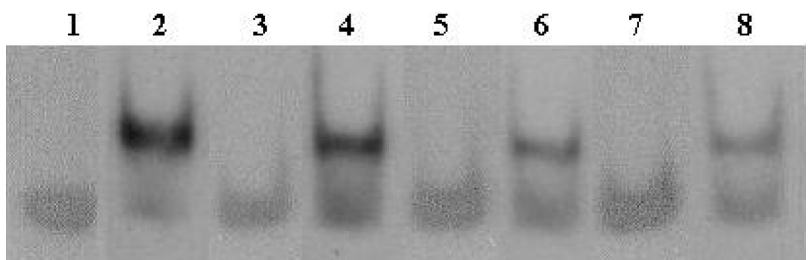

Fig. 3. The effect of cooling of the pre-heated L1 repressor on the operator DNA-binding activity. The autoradiograph showing the extent of refolding of both the CI and CIts391 repressors preheated at different temperatures. See Materials and Methods for details. Lanes 2, 4, 6 and 8, contained the assay mixture carrying the wild-type repressors preincubated at 42, 45, 48 and $52^{\circ} \mathrm{C}$, respectively. Lane 1 contained ${ }^{32} \mathrm{P}$ end labeled operator DNA only. In the rest of the lanes, the CIts391 repressors, preincubated at 42,45 and $48^{\circ} \mathrm{C}$, were loaded after their reactions.

\section{Heat-treated wild-type repressor CI regains its DNA-} binding activity after gradual cooling The loss of DNAbinding activity in the above two repressors suggests that the active conformations of the repressor proteins are changed to inactive forms at higher temperatures. To test if such changes of the conformations of the repressor proteins were reversible or irreversible, the DNA-binding activities of the heat-treated repressors were determined after their slow cooling. As shown in Fig. 3 (lane 2), the wild-type repressor was estimated to shift by around $80 \%$ that of the input operator when cooled to $32^{\circ} \mathrm{C}$ after heating at $42^{\circ} \mathrm{C}$. This indicates that the wild-type repressor substantially regained its DNA-binding activity as it showed only about $40 \%$ DNA-binding activity at $42^{\circ} \mathrm{C}$ (Fig. 2, lane 8). In addition, around 45-60\% DNA-binding activity was shown when cooled slowly to $32^{\circ} \mathrm{C}$ after preincubation at temperatures from 45 to $52^{\circ} \mathrm{C}$ (Fig. 3, lanes 4, 6 and 8). This is highly surprising as the wild-type CI was found not to bind the operator DNA at a significant level when the binding assays were carried out directly between 45 and $52^{\circ} \mathrm{C}$ (data not shown). Contrary to the above, the CIts391 repressor was

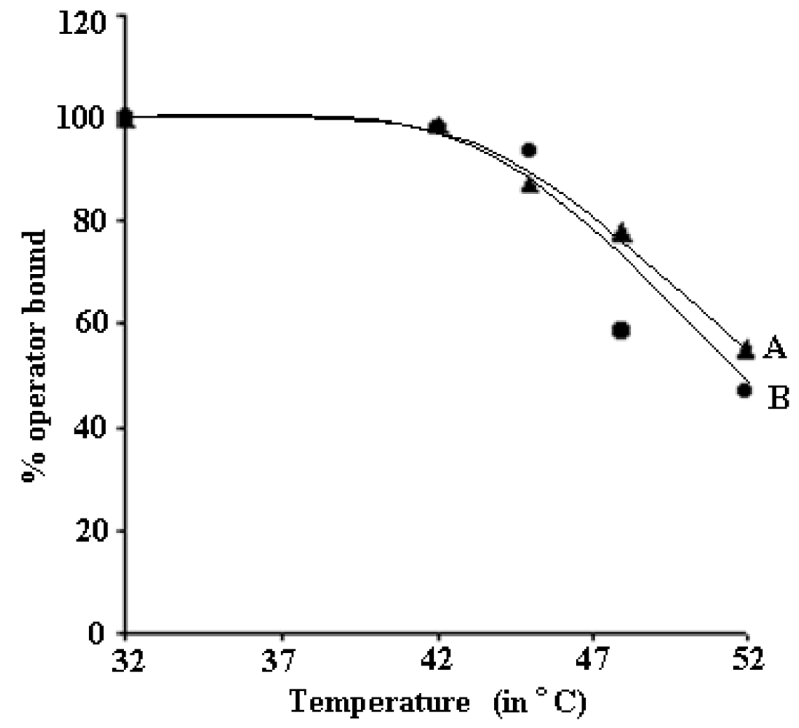

Fig. 4. The difference in stability between the wild type CI and CIts391 repressor operator complexes at different temperatures. The plot of $\%$ operator bound versus temperature show the varying degrees of resistance of the CI-(curve A) or CIts391(curve B) operator complexes to dissociation at $32-52^{\circ} \mathrm{C}$. As described in Materials and Methods, the amount of repressorbound operator, not undergoing dissociation on shifting the reaction mixtures from 0 to $32,42,45,48$ and $52^{\circ} \mathrm{C}$, respectively, were determined from a gel shift assay picture, and then plotted. The amount of repressor-bound operator at $32^{\circ} \mathrm{C}$ was defined as $100 \%$.

observed not to regain its DNA-binding activity to an appreciable level, even when cooled slowly to $32^{\circ} \mathrm{C}$ after 30 min preincubation at $42^{\circ} \mathrm{C}$ (Fig. 3, lane 3). These results differ from the observation with some of the temperature-sensitive mutant repressors of phage $\lambda$, which regained substantial amounts of DNA binding activities under similar treatments (Mandal and Leib, 1976). However, our results suggest that the $131^{\text {st }}$ proline residue of the L1 repressor plays crucial roles in maintaining its active form and in the binding of the repressor to the cognate operator.

Stability of repressor-operator complex at different temperatures It was shown that a mutant repressor of bacteriophage P1 could not bind with its operator DNA in the temperature ranging 40 to $45^{\circ} \mathrm{C}$, but the repressor-operator complex formed at room temperature was somewhat resistant to the above temperatures (Heinrich et al., 1989). To see whether the CIts391 repressor of L1 behaves in a similar way, the stability of the CIts391-operator DNA complexes preformed at $0^{\circ} \mathrm{C}$ was checked by the gel shift assay after 20 min incubation at 32 to $52^{\circ} \mathrm{C}$. As shown in Fig. 4, the complexes had varying degrees of resistance to dissociation during incubation at the above temperatures (curve B). The preformed CI-operator DNA complexes were also found to be heat-tolerant within the above temperature range (Fig. 4, 


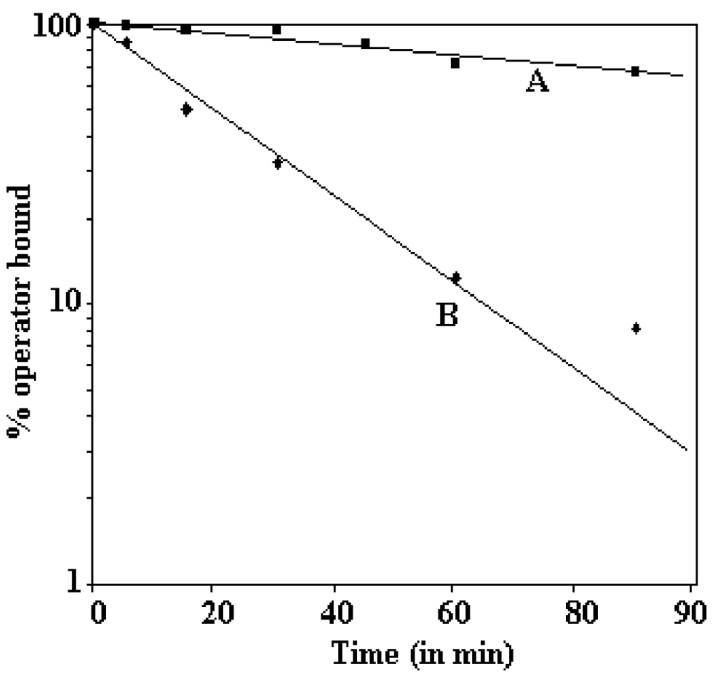

Fig. 5. Dissociation of the repressor-operator complexes at $32^{\circ} \mathrm{C}$. The amount of repressor-bound operator, remaining undisturbed for 0-90 min after the addition of excess cold operator DNA, were determined from gel shift assay pictures, and then plotted against time. For details, see Materials and Methods. The amount of operator bound in the shifted complex of the zero time aliquot was defined as $100 \%$. Curves: A, wild-type repressor and B, CIts391 repressor, respectively.

Curve A). The only difference between the two types of complex is that the CI-operator complexes are slightly more stable than those of the CIts391-operator at temperatures above $42^{\circ} \mathrm{C}$ (curves A versus B). In general, about $45-98 \%$ of either type of complex was found to be unperturbed between 42 and $52^{\circ} \mathrm{C}$ compared to that at $32^{\circ} \mathrm{C}$. Such results, however, were unexpected compared to the observation mentioned above (Fig. 2). Also, this can not properly explain how the L1cIts391 lysogen in M. smegmatis is induced and lysed at $42^{\circ} \mathrm{C}$ (Chaudhuri et al., 1993), when the CIts391 repressoroperator complex is resistant to a certain extent at this nonpermissive temperature. This indicates that some other regulators may also be involved in the induction of the above lysogen at non-permissive temperatures.

Plating efficiency of L1cI- phage on $M$. smegmatis strains carrying the wild-type cI and cIts391 repressor genes Both the wild-type L1 and its mutant L1cIts391 phages form turbid plaques on the lawn of $M$. smegmatis at $32^{\circ} \mathrm{C}$ (Chaudhuri et al., 1993). Our in vitro data have also shown (above) that both the repressors bind well with the same operator DNA at $32^{\circ} \mathrm{C}$. To test whether the two repressors behave similarly in vivo, the efficiency of the plating of $\mathrm{L} 1 c \mathrm{I}^{-}$ (Chaudhuri et al., 1993) on M. smegmatis mc $^{2} 155$ carrying either the wild-type or the $c \mathrm{I} t s 391$ repressor genes was measured. To this end, the plasmids pCP1 and pCP2 (Sau et al., 2004) were constructed by cloning the wild-type $c$ I and cIts391 genes into pSD5S30 (Jain et al., 1997). Next, L1cI ${ }^{-}$ phages were plated on $M$. smegmatis $\mathrm{mc}^{2} 155$ carrying either pCP1 or pCP2, and the efficiencies of the plating of $\mathrm{L} 1 \mathrm{I}^{-}$as well as its plaque size were determined at both 32 and $42^{\circ} \mathrm{C}$, and the data are presented in Table 1. At either temperature, both the efficiency of the plating (e.o.p) of $\mathrm{L} 1 c \mathrm{I}^{-}$phages and the plaque size determined on $\mathrm{mc}^{2} 155(\mathrm{pCP} 2)$ were increased significantly compared to those on $\mathrm{mc}^{2} 155$ (pCP1), but reduced to an extent comparable with those on $\mathrm{mc}^{2} 155$ (pSD5S30). The reduction of both the determinants, especially at $42^{\circ} \mathrm{C}$, most possibly occurred due to assaying the $\mathrm{L} 1 c \mathrm{I}^{-}$phage at room temperature. However, these results suggest that the wild-type repressor gene of pCP1 is more active in repressing the growth of $\mathrm{L} 1 c \mathrm{I}^{-}$compared with that of the cIts391 repressor gene at both 32 and $42^{\circ} \mathrm{C}$. It was interesting to note that the $\mathrm{L}_{1} \mathrm{cI} \mathrm{I}^{-}$phages were unable to form plaques on either the wild-type L1 lysogen or L1cIts391 lysogens in $\mathrm{mc}^{2} 155$ at $32^{\circ} \mathrm{C}$ (data not shown). This may have been that the levels of expression of the repressors by pCP1 and $\mathrm{pCP} 2$ were less than those of the lysogens.

Half-lives of the repressor-operator complexes The reduced level of repression of L1cI' phage growth by CIts391, as found above, may have been due to the weaker binding of CIts391 to the operator DNA than that of the wild-type CI at $32^{\circ} \mathrm{C}$. To test this hypothesis, the rate of dissociation of the CIts391-operator complex was compared with that of the wild-type CI-operator complex at $32^{\circ} \mathrm{C}$. As shown in Fig. 5, the rate of dissociation of the CIts391-operator complex was much higher than that of the CI-operator complex at $32^{\circ} \mathrm{C}$. While the half-life of the latter complex was estimated to be $160 \mathrm{~min}$, that of the former was only $20 \mathrm{~min}$. On the contrary, at $0^{\circ} \mathrm{C}$, the half-lives of the two complexes were 90 and 130 min, respectively (data not shown). These results suggest that the operator binding activity of CIts391 is weaker than that of

Table 1. Plating of $\mathrm{L} 1 c \mathrm{I}^{-}$phages on $M$. smegmatis $\mathrm{mc}^{2} 155$ carrying different plasmids

\begin{tabular}{|c|c|c|c|c|c|}
\hline \multirow{2}{*}{$\begin{array}{l}\text { M. smegmatis } \\
\text { Strains }\end{array}$} & \multirow{2}{*}{$\begin{array}{l}\text { Repressor gene } \\
\text { present }\end{array}$} & \multicolumn{2}{|c|}{ Percent e.o.p* of $\mathrm{L} 1 c \mathrm{I}^{-}$} & \multicolumn{2}{|c|}{ Diameter of plaque $(\mathrm{mm})$} \\
\hline & & $32^{\circ} \mathrm{C}$ & $42^{\circ} \mathrm{C}$ & $32^{\circ} \mathrm{C}$ & $42^{\circ} \mathrm{C}$ \\
\hline $\mathrm{mc}^{2} 155(\mathrm{pSD} 5 \mathrm{~S} 30)$ & nil & 100 & 100 & 2.5 & 3.0 \\
\hline $\mathrm{mc}^{2} 155(\mathrm{pCP} 1)$ & $c \mathrm{I}$ & 9.5 & 20 & 0.5 & 1.8 \\
\hline $\mathrm{mc}^{2} 155(\mathrm{pCP} 2)$ & cIts391 & 22 & 63 & 1.0 & 2.5 \\
\hline
\end{tabular}

*The efficiency of plating (e.o.p) was determined by dividing the plaque-forming units on M. smegmatis mc ${ }^{2} 155$ carrying either pCP1 or pCP2 by those formed on M. smegmatis $\mathrm{mc}^{2} 155$ harboring pSD5S30. See text for details. 
the wild-type repressor at $32^{\circ} \mathrm{C}$.

Acknowledgments We thank Drs. B. Bloom, S. Yasuda and Anil Tyagi for the several strains, such as mycobacteriophage L1, M. smegmatis, and plasmids, like pMPMK4 and pSD5S30. The technical assistance of Mr. N. C. Datta is thankfully acknowledged. This research work was supported by the Junior Research fellowships to Mr. Tridib Ganguly (from the CSIR, Govt. of India, New Delhi) Mr. Partho Chattoraj and Mr. Palas Chanda (both from UGC, Govt. of India, New Delhi).

\section{References}

Ausubel, F. M., Brent, R., Kingston, R. E., Moore, D. D., Seidman, J. G., Smith, J. A. and Struhl, K. (ed.) (1998) Current Protocols in Molecular Biology, Vol. 2, pp. 12.2.112.2.11 copyright by John Wiley \& Sons, Inc., USA.

Bradford, M. M. (1976) A rapid and sensitive method for the quantitation of microgram quantities of protein utilizing the principle of protein-dye binding. Anal. Biochem. 72, 248-254.

Brown, K. L., Sarkis, G. J., Wadsworth, C. and Hatfull, G. F. (1997) Transcriptional silencing by the mycobacteriophage L5 repressor. EMBO J. 16, 5914-5921.

Chattopadhyay, C., Sau, S. and Mandal, N. C. (2003) Cloning and characterization of the promoters of temperate mycobacteriophage L1. J. Biochem. Mol. Biol. 36 , 586-592.

Chaudhuri, B., Sau, S., Datta, H. J. and Mandal, N. C. (1993) Isolation, characterization and mapping of temperature-sensitive mutations in the genes essential for lysogenic and lytic growth of the mycobacteriophage L1. Virology. 194, 166-172.

Doke, S. (1960) Studies on mycobacteriophages and lysogenic mycobacteria. Kumamoto Med. J. 34, 1360-1373.

Donnelly-wu, M. K., Jacobs, W. R. Jr. and Hatfull, G. F. (1993) Superinfection immunity of mycobacteriophage L5: application for genetic transformation of mycobacteria. Mol. Microbiol. 7, 407-417.

Hatfull, G. F. (2000) Molecular Genetics of Mycobacteriophages;
In Molecular Genetics of Mycobacteria, Hatfull, G. F. and Jacob, W. R., Jr. (eds.), pp. 37-54, ASM Press, Washington D.C., USA.

Heinrich, J., Riedel, H-D., Baumstark, B. R., Kimura, M. and Schuster, H. (1989) The cI repressor of bacteriophage P1 operatorrepressor interaction of wild-type and mutant repressor proteins. Nucl. Acids Res. 17, 7681-7692.

Jain, S., Kaushal, D., DasGupta, S. K. and Tyagi, A. K. (1997) Construction of shuttle vectors for genetic manipulation and molecular analysis of Mycobacteria. Gene 190, 37-44.

Jana, N. K., Roy, S., Bhattacharyya, B. and Mandal, N. C. (1999) Amino acid changes in the repressor of bacteriophage lambda due to temperature-sensitive mutations in its cI gene and the structure of a high temperature-sensitive mutant repressor. Protein Eng. 12, 225-233.

Mandal, N. C. and Leib, M. (1976) Heat-sensitive DNA-binding activity of the cI product of bacteriophage Lambda. Molec. Gen. Genet. 146, 299-302.

Mayer, M. P. (1995) A new set of useful cloning and expression vectors derived from pBlueScript. Gene. 163, 41-46.

Ouyang, S., Sau, S. and Lee, C. Y. (1999) Promoter analysis of the cap 8 operon, involved in type 8 capsular polysaccharide production in Staphylococcus aureus. J. Bacteriol. 181, 24922500.

Sau, S., Chattoraj, P., Ganguly, T., Lee, C. Y. and Mandal, N. C. (2004) Cloning and sequencing of the repressor gene of temperate mycobacteriophage L1. J. Biochem. Mol. Biol. 37, 254-259.

Snapper, S. B., Lugosi, L., Jekkel, A., Melton, R. E., Kieser, T., Bloom, Br. and Jacobs, W. R. Jr. (1988) Lysogeny and transformation in mycobacteria: stable expression of foreign genes. Proc Natl Acad Sci. USA. 85, 6987-6991.

Sambrook, J. and Russell, D. W. (2001) Molecular Cloning: A Laboratory Manual. 3rd ed., Cold Spring Harbor Laboratory Press, Cold Spring Harbor, New York, USA.

Vogel, J. L., Li, Z. J., Howe, M. M., Toussaint, A. and Higgins, N. P. (1991) Temperature-sensitive mutations in the bacteriophage $\mathrm{Mu} \mathrm{c}$ repressor locate a 63-amino acid DNAbinding domain. J. Bacteriol. 173, 6568-6577. 